Darcy, S., \& Harris, R. (2003). Inclusive and accessible special event planning: an Australia perspective. Event Management, 8(1), 516-536.

\title{
INCLUSIVE AND ACCESSIBLE SPECIAL EVENT PLANNING: AN AUSTRALIAN
}

\section{PERSPECTIVE}

Simon Darcy

Senior Lecturer

School of Leisure, Sport and Tourism

Faculty of Business

University of Technology, Sydney

Tel: 612 9514-5100; fax: 612 9514-5195; email: Simon.Darcy@uts.edu.au

Rob Harris

Senior Lecturer

School of Leisure, Sport and Tourism

Faculty of Business

University of Technology, Sydney

Tel: 612 95145496; fax: 612 9514-5195; email: Rob.Harris@uts.edu.au

\section{ABSTRACT}

People with disabilities have a right to access the full range of social activities and services available in a society. Nonetheless, the way that the built and social environments are constructed restrict access of the group to participation, and hence, their rights of citizenship. This paper looks at how those engaged in the organisation of events can facilitate the involvement of people with disabilities in the conferences, festivals, and sporting events that they conduct. The paper begins by providing a brief overview of selected statistics and legislation associated with disability in Australia. The paper then looks at the operationalization of event planning in Australia through a review of complaint cases made under the Disability Discrimination Act, 1992. The review provides an insight into the current discriminatory practices employed by event and venue managers. The paper then presents a 'best practice' case study of the Sydney 2000 Olympic and Paralympic Games to show how disability and access issues were incorporated into the event planning and operations processes. The paper concludes with some directions that event and venue managers may employ to better incorporate people with disabilities within their programs. 


\section{INTRODUCTION}

People with disabilities comprise a significant component of the population of any community, yet until relatively recent times they were marginalised from community participation. This paper reviews this situation in the Australian context through the field of event management. The paper begins by providing a brief overview of selected statistics and legislation associated with disability in Australia. The paper then looks at the operationalization of event planning in Australia through a review of complaint cases made under the Disability Discrimination Act, 1992. The review provides an insight into the current discriminatory practices employed by event and venue managers. The paper then presents a 'best practice' case study of the Sydney 2000 Olympic and Paralympics Games (the Games) to show how disability and access issues were incorporated into the event planning and operations processes. The paper concludes with some directions that event and venue managers may employ to better incorporate people with disabilities within their programs.

\section{DISABILITY IN AUSTRALIA: AN OVERVIEW}

Disability needs to be considered as part of human diversity and not separate from it. All societies contain individuals with disabilities, with approximately 500 million people world wide living with disability. (Charlton 1998). In the Australian context, disability as a proportion of the population has steadily increased from $15 \%$ to $19 \%$ since the national survey was first undertaken in 1988 (Australian Bureau of Statistics 1998). In 1998 an estimated 3.6 million people, or $19 \%$ of the Australian population were classified as having a disability. There is also a significant relationship between ageing and disability whereby a person is 14 times more likely to have a disability by the time they reach 65 years of age than they were as a four year old (ABS 1998). Australia has an ageing population (Australian Bureau of Statistics 1996) and the numbers and proportion of older people in Australia is growing dramatically for a number of reasons (Lynch and Veal 1996:329-332).

Of this group, approximately 500,000 use mobility aids, 280,000 are Deaf or have a hearing impairment, 260,000 have a mood or behavioural disabilities, 160,000 have learning disabilities and 115,000 people who are Blind or have a vision impairment (ABS 1998:23). In addition to those identified as having some form of disability, another 3.1 million individuals were classified as having a condition or impairment that, while currently having no significant impact on their daily lives, would likely result in some form of disability in the future (ABS 
1998). As shown in Table 1, the Australian statistics are similar to other Western nations who also share similar patterns of the ageing of the population.

Table 1: Comparative estimates of disability rates

\begin{tabular}{|c|c|c|c|c|}
\hline Country & $\begin{array}{l}\text { Year of } \\
\text { Survey }\end{array}$ & $\begin{array}{l}\text { Population } \\
\text { (Million) }\end{array}$ & $\begin{array}{l}\text { Percent of } \\
\text { Population }\end{array}$ & $\begin{array}{c}\text { People with } \\
\text { Disabilities } \\
\text { (Million) }\end{array}$ \\
\hline Australia * & 1998 & 18.6 & 19.6 & 3.6 \\
\hline New Zealand * & 1996 & 3.6 & 19.1 & 0.7 \\
\hline Canada $*$ & 1991 & 30.6 & 15.5 & 4.7 \\
\hline USA & 2000 & 270.3 & 19.5 & 52.7 \\
\hline European $* *$ & & & & \\
\hline Austria & 1995 & 8.1 & 12.5 & 1.0 \\
\hline Belgium & 1997 & 10.2 & 12.9 & 1.3 \\
\hline Denmark & 1995 & 5.3 & 17.4 & 0.9 \\
\hline Germany & 1998 & 82.0 & 17.3 & 14.2 \\
\hline Greece & 1991 & 10.6 & 8.2 & 0.9 \\
\hline Spain & 1999 & 39.1 & 9.9 & 3.9 \\
\hline France & 1999 & 58.8 & 15.3 & 9.0 \\
\hline Finland & 2000 & 5.1 & 22.9 & 1.2 \\
\hline Ireland & None Avail & 3.6 & 10.9 & 0.4 \\
\hline Italy & 1994 & 56.8 & 7.8 & 4.4 \\
\hline Luxembourg & Exp Est. & 0.4 & 16.5 & 0.1 \\
\hline Netherlands & 1999 & 15.7 & 18.6 & 2.9 \\
\hline Portugal & None Avail & 9.9 & 18.4 & 1.8 \\
\hline Sweden & 1999 & 8.9 & 17.1 & 1.5 \\
\hline UK & 2000 & 57.7 & 18.8 & 10.8 \\
\hline Total & & & & 232.6 \\
\hline
\end{tabular}

* denotes definition by activity limitation Takamine (2001); ** based on European Community Household Panel estimates (van Lin, Prins, and Zwinkels 2001)

Sources: Takamine (2001), van Lin et al. (2001), Pfieffer (2002) and Chamie (1995) cited in Wen and Fortune (1999:12). Population estimates from http://www.census.gov/ipc/www/wp98.html

The NSW Government (1997) and the CDFACS (1999a) establish dimensions for access based on broad categories of disability. For example, CDFACS define the physical access needs of people with vision; hearing; cognitive; mobility and manipulative impairments. They state that each impairment group has a variety of access considerations. The NSW Government (1997) simplifies this further by relating exclusion to social participation and highlighting the dimensions of access that restrict social participation as physical, sensory and communication dimensions. For example, who use a wheelchair or walking aid, may need a continuous pathway ${ }^{1}$ comprised of ramps, lifts, handrails, kerb cuts and wide doorways etc in order to access an event and move around within an event site/venue. Sensory access involves

1 "An uninterrupted path of travel to or within a building providing access to all required facilities. For non-ambulatory people, this accessible path shall not incorporate any step, stairwell or turnstile, revolving door, escalator or other impediment which would prevent it being negotiated by people with a disability.” (Standards Australia, 1993:7) 
a different set of needs such as hearing augmentation-listening systems, tactile signs, sign language interpreters, and audio cues for lifts. Communication access involves providing information in alternative formats (Braille, large print or plain English) to facilitate participation (Disability Council of NSW 1994).

In recent years, human rights legislation has been introduced into many Western nations designed to try and ensure that people with disabilities are not discriminated against. At the Australian Federal level the Disability Discrimination Act (DDA), 1992 was introduced for and sought to eliminate discrimination against people with disabilities. The DDA also aimed to promote community acceptance that people with disabilities have the fundamental rights before the law as the non-disabled. From an event management perspective planning practices need to incorporate the dimensions of access for these disability groups. The DDA, along with complementary State disability policy, environmental planning legislation, Building Codes of Australia (Australian Building Codes Board 1996), the referenced Australian Standards for access and mobility (Standards Australia 1992a; 1992c; 1992b; 1998) seek to ensure that the access needs of people with disabilities are adequately met. The body responsible for overseeing, and dealing with complaints flowing from the DDA is the Human Rights and Equal Opportunity Commission (HREOC) (HREOC 2001b). The following section reviews the complaints cases instigated under the DDA that involved events related issues.

\section{THE DISABILITY DISCRIMINATION ACT AND EVENTS}

The DDA makes it unlawful for an event organiser to discriminate against people with disabilities in the areas of access to public places, education and the provision of goods, services and facilities. A review of complaint cases for this paper found a number of significant complaint cases that implications for the events industry. The most numerous of the cases involved physical access to premises, the provision of information and the equality of service provision. A number of complaint cases are outlined:

- Arts festival access- an event organiser had booked an inaccessible venue, a hall at Adelaide University, for their arts festival. Two separate complaints were lodged, one by an exhibitor and the other by a person who wished to attend the festival. The conciliated 
outcome required the festival to be moved to an accessible venue and for Adelaide University to commit funds to make the hall accessible for future events.

- Conference and ticket fees - two complaint cases identified that it was discriminatory to charge a second fee (Conference registration or ticket purchase) to an attendant of a person with a disability attending an event if the attendant was there only to facilitate the person with a disability's involvement. Both these complaint cases were settled through a refund of the second fee charged and organizations changing their charging policy. Many organizations now have a recognized 'attendant, carer or companion' policy for people with disabilities who require the assistance of an attendant.

- Stadium access - a man who uses a wheelchair lodged a complaint concerning the lack of accessible seating at a newly constructed major sports venue. The outcome of the ensuing mediation involved the venue agreeing to develop a policy for seating complying with the most recent Building Code of Australia edition. This ensured that at least 1 in 200 seats would in future be wheelchair accessible; and that priority would be given to people with disabilities when booking these seats up until one week before an event.

- Function room access - a man who uses a wheelchair lodged a complaint concerning the inaccessible features of function rooms operated by a local council. He was attending a wedding and had been advised that the rooms were accessible and had a lift. Upon arrival, he found the lift to be a goods lift which was too narrow and did not operate easily even with staff assistance. He was subsequently unable to reach the toilet (which was on a different floor) in time, had to leave to change clothes and missed the event. The mediated outcome involved: the council agreeing to install a lift complying with standards for passenger use; the conduct of staff disability awareness training; and the payment of financial compensation to the complainant.

- Information provision - a blind man lodged two separate a complaints cases against the Sydney Organising Committee for the Olympic Games (SOCOG). He stated that he had been discriminated against by the failure to produce the official ticket book in Braille and the official website of the Games was not compliant with the W3C guidelines for website accessibility. The HREOC determined that discrimination had occurred, either on the basis of less favourable treatment or on the basis that a condition or requirement had been 
imposed that the complainant could not comply with and which was unreasonable. The complaints were upheld and while originally ignored by SOCOG further action was taken to the Federal Court of Australia where an undertaking was given to provide alternative format information for the future and to compensate the individual involved.

- Quality of viewing experience - A man who has quadriplegia and uses a wheelchair lodged a complaint concerning the wheelchair accessible seating in a recently constructed tennis centre and aquatic centre. He was of the opinion that the seats had poor lines of sight as railings at eye height made it difficult to see. The complaint was settled by the venue agreeing to both reducing the height of the main balustrades to $800 \mathrm{~mm}$, and to installing thin steel cables (which do not block the view) for safety (HREOC 2002).

These complaint cases identify discriminatory practice by event and venue managers in Australia. In 2000/2001 some 505 complaint cases were finalized involving conciliation hearings and Federal Court actions (HREOC 2001a). Many of these cases could have been avoided through understanding the responsibilities of the DDA on providers of facilities and services. An awareness of these responsibilities would have saved people with disabilities from discriminatory practices that led to dissatisfying experiences. Further, it would have saved providers the time and resources required to resolve these complaint cases.

The DDA through Disability Action Plans (DAP) has a strategic mechanism to proactively engage disability and access issues. The advantage to organisations are that the DAP becomes a consideration if a complaint is made against the organisation (HREOC 2002). To date only one event, the National Folk Festival (NFF), has gone down the path of developing a DAP (HREOC 2002). The NFF's plan aims to “ ensure that the National Folk Festival is recognised as providing accessible mainstream access, and services, to all people". In pursuing this goal it has focused its attention on improving on-site access for attendees, staff and volunteers, and on ensuring on-site services, activities and performances can be accessed/enjoyed by people with disabilities. In order to progress these broad objectives, the NFF states in this plan that it will:

- appoint an access coordinator; introduce disability liason officers (4- 6 people);

- consult with attendees with disabilities and/or their associated organisations;

- use feedback to annually update the access plan; 
- provide access information on their website; and

- provide disability awareness training to all staff and volunteers" (National Folk Festival, 2002).

It is noteworthy that the proactive stance by the NFF as regards access would appear not be typical of events of this type. Using the New South Wales Folk Association listing of folk festivals in that state, the authors of this paper undertook a review of the websites of those events listed (18 of the 35 festivals listed had websites). Only one event (Global Carnival 2000) made mention of access issues (HREOC 2002). A more extensive study would be needed to establish the extent to which such an outcome would apply to other event types, however, the authors are of the opinion that it is likely this finding would be generalisible, at least in the festivals area.

While SOCOG was cited in one of the previously mentioned complaint cases, the Games nonetheless represented the most extensive effort that has yet been made by an event in Australia to provide an inclusive experience for people with disabilities (Olympic Coordination Authority 2001). SOCOG, while organising the Games, was not the main body responsible for disability and access issues. This was the responsibility of the Olympic Coordination Authority (OCA), a New South Wales (NSW) state government authority specifically chartered to develop the venues, operate the sites during Games and maintain the sites for future. This involved cross agency coordination, the responsibility under the DDA and NSW environmental planning legislation for access issues. An extensive review of agency responsibilities has been undertaken elsewhere (Darcy 2001). OCA's approach to these issues provides significant insights into the processes involved in planning and delivering inclusive events. The final part of this paper overviews the efforts of delivering and inclusive event.

\section{THE SYDNEY 2000 OLYMPIC GAMES}

The Games occurred over three months and included the Olympics, Paralympics and the Cultural Olympiad that surrounds both events. The access planning framework used for the Games by OCA is presented in Figure 1. To ensure the process outlined in this framework worked effectively an Access Advisory Committee (AAC) was established. This committee's function was to advise the OCA on the full range of issues associated with disability and 
access. The AAC drew its members from various community organisations with expertise in the area (see Table 2), and operated within a set of self developed operating principals, specifically:

- people with disabilities are people first

- a person with a disability is a full and valued member of society

- a person with a disability may work in, compete in or visit any building or venue

- where operational solutions are necessary, the person is to be treated with dignity and their energy conserved

- $\quad$ staff and volunteers must be willing and able to assist a person with access requirements when requested

- where a person with a disability requires the use of a personal assistant, they are to remain with them at all times

- a person with a disability will have access to the services provided to the general public, at no greater cost

- the legal rights of a person with a disability will be recognised and protected

- $\quad$ services will be sensitive to and support the diversity of people with disabilities

- inquiries and complaints will be taken seriously and dealt with speedily. 
Figure 1: Accessibility Planning Framework for the Sydney 2000 Olympic Games

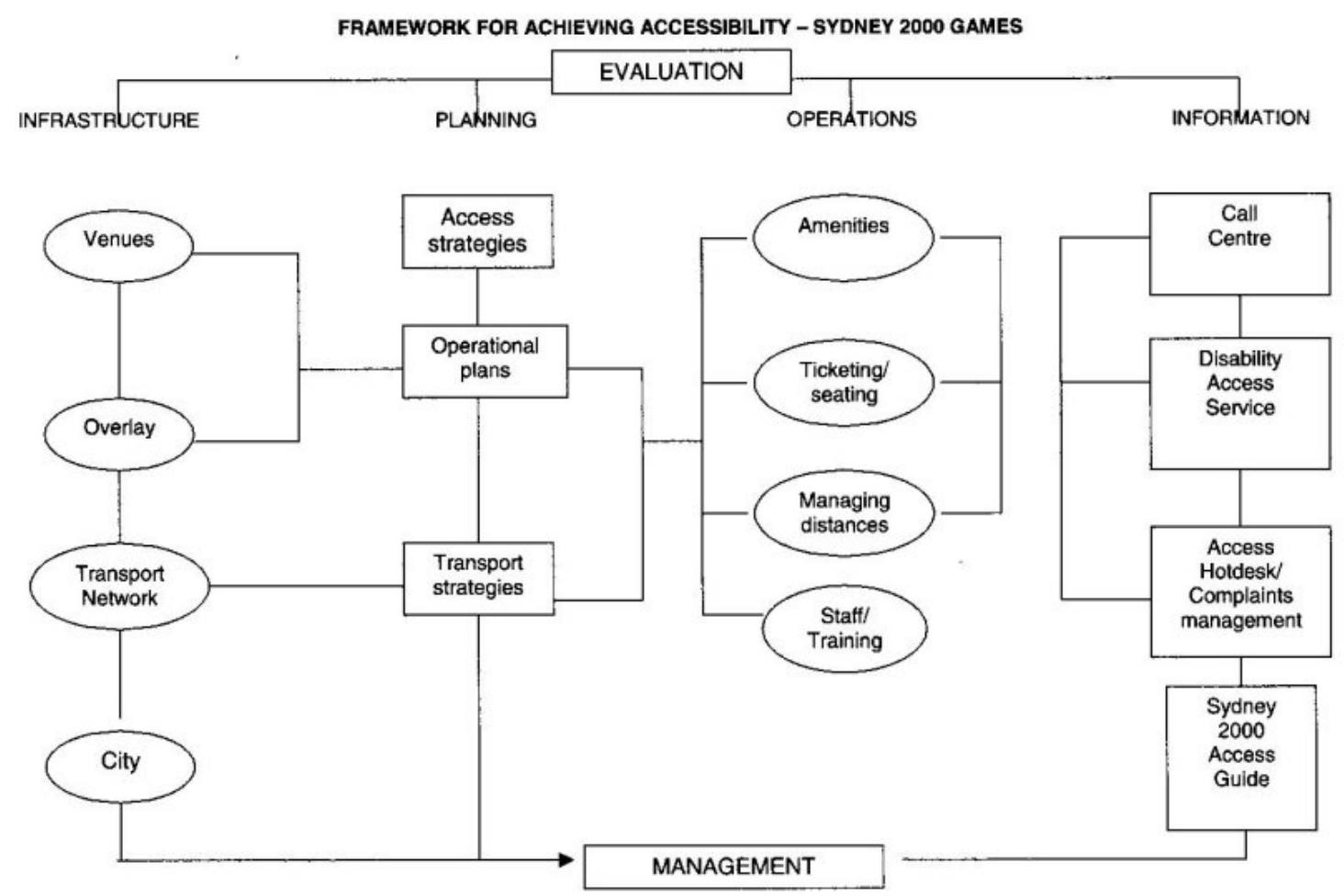

Source: OCA, 2001

Table 2: Membership and Affiliation of the Olympic Access Advisory Committee

\begin{tabular}{|ll|}
\hline Government Agencies & Peak Disability and Community Groups \\
\hline Ageing and Disability Department & Acrod Limited, NSW \\
Department of Transport & NSW Council for Intellectual Disability \\
SOCOG & Self Help for the Hard of Hearing \\
SPOC & National Federation of Blind Citizens \\
Anti Discrimination Board & Consultative Committee on Ageing \\
Disability Council of NSW & People with Disabilities NSW Inc. \\
Government Architect Design Directorate & National Federation of Blind Citizens \\
\hline Source: OCA, 2001 &
\end{tabular}

One of the main tasks of the AAC was to produce a set of Access Guidelines to incorporate disability and access issues for inclusion in the Games planning process from the beginning (OCA 1996). These guidelines incorporated current access requirements stipulated in the Building Codes of Australia (Australian Building Codes Board 1996), the referenced Australian Standards for access and mobility (Standards Australia 1992a; 1992c; 1992b; 1998), and the spirit and intent of the DDA. The Access Guidelines that sought to incorporate access for all dimensions of disability and in all of the roles that the Games provide for people with disabilities as athletes, performers, spectators, officials, media, volunteers and staff. They sought to provide people with disabilities with an accessible environment that they can function in independently and with equity and dignity (Olympic Co-ordination Authority 1998). As the Guidelines state, 
Access is not only about buildings. A truly accessible environment is one in which a person with a disability can freely express their independence, and one in which any impediment to integration is removed. It involves "seamless" blending of numerous key components such as communication, transport, employment, education, external pathways, community awareness, housing and buildings. Special access provisions should not be necessary if the environment is built to adequately reflect the diversity and needs of the community (OCA 1998:3).

This quote emphasises the importance of conceptualizing access as part of the universal design process (Aslaksen, Bergh, Bringa, and Heggem 1997; Preiser and Ostroff 2001). Universal design regards disability as part of human diversity and central to maximizing community participation. Disability and access issues are not a 'special' addition and not to incorporate these issues is economically and socially inefficient. The guidelines were issued to all professionals involved in OCA developments. OCA employed these principles in the planning, design, construction, operations and information provision stages together with a thorough monitoring process at each stage through the involvement of the AAC. This process required that an access strategy be prepared for each venue and that an access audit be carried out. Further, these requirements were extended to include the Cultural Olympiad venues, and were interpreted as embracing any other necessary services that would be considered part of the Games 'precinct' (e.g. hospitals). In the light of new developments in the access area, and of experience in the application of the original guidelines, a revised second edition was released prior to the Games in 1998 (OCA 1998).

The access objectives and their associated strategies and/or policies that emerged from the interaction between the OCA and the ACA are summarised in Table 3 .

Table 3: Sydney 2000 Games, Access Strategies and Policies

\begin{tabular}{|ll}
\hline Objective & Key Policies And/Or Strategies \\
The capacity to plan ahead & $\begin{array}{l}\text { Access Guide to the Games; SOCOG and Olympic Rail and Traffic } \\
\text { Authority call centres; pre-booked parking (Paralympics only); State Library } \\
\text { Disability Access Service }\end{array}$ \\
Venue and return & $\begin{array}{l}\text { Accessible transport strategy; State Rail management of } \\
\text { assistance at stations; accessible parking at park and rides; } \\
\text { accessible shuttles; accessible regional buses; accessible taxi } \\
\text { drop-off point (Sydney Olympic Park); accessible parking at key } \\
\text { railway stations (Central, Redfern, Lidcombe, Granville, }\end{array}$ \\
& $\begin{array}{l}\text { Blacktown, Strathfield and Liverpool) and in the city; accessible } \\
\text { parking at Sydney Olympic Park (Paralympics only); audit of } \\
\text { pedestrian routes in city }\end{array}$ \\
Ticketing policy; training - call centre staff; identification of \\
access requirements and follow up; seating policy; wheelchair
\end{tabular}




\begin{tabular}{|c|c|}
\hline & $\begin{array}{l}\text { and companion seats in all venues; enhanced seating identified } \\
\text { in all venues; ramps, handrails, etc, as per OCA Access } \\
\text { Guidelines }\end{array}$ \\
\hline $\begin{array}{l}\text { Accessible food and drink, concessions } \\
\text { and other amenities }\end{array}$ & $\begin{array}{l}\text { Concessions and merchandising policy; some lower counter } \\
\text { heights; accessible locations, eg hardstand; \% of accessible } \\
\text { toilets. Compliance monitored daily }\end{array}$ \\
\hline The capacity to move around independently & $\begin{array}{l}\text { Wayfinding, colour contrast, size and height; use of accessible (disability) } \\
\text { pictograms, including where assisted access } \\
\text { required; tactile maps for legacy; use of braille in some venues }\end{array}$ \\
\hline Live-time information & $\begin{array}{l}\text { FM induction systems; PA system and hearing loop; captioning } \\
\text { on some score boards and video screens; closed captioning for } \\
\text { live broadcast }\end{array}$ \\
\hline Assistance as needed & $\begin{array}{l}\text { Spectator Services and Village staff training; wheelchair loan } \\
\text { Arrangements }\end{array}$ \\
\hline Integration & $\begin{array}{l}\text { Wheelchair spaces in buses; sit people together wherever } \\
\text { Possible }\end{array}$ \\
\hline Affordability & $\begin{array}{l}\text { Use of public transport maximised; range of ticketing prices -concessions } \\
\text { (Paralympics); free parking (Paralympics) }\end{array}$ \\
\hline Strategies to minimise distances to travel & $\begin{array}{l}\text { Closer drop-off points to venues; wheelchair loan arrangements; } \\
\text { separate pathways only to reduce distance }\end{array}$ \\
\hline Accessible accommodation (for athletes) & $\begin{array}{l}\text { Additional accessible bathrooms; completely accessible pathway } \\
\text { of travel in Village; Village access strategy - 5\% adaptable and } \\
30 \% \text { visitable houses (in legacy), } 21.4 \% \text { of bed spaces are } \\
\text { accessible for the Paralympics }\end{array}$ \\
\hline No undue exposure to risk & $\begin{array}{l}\text { Specifically addressed in contingency planning and VERPs; } \\
\text { Spectator Services training; hazard tiles; handrails; daily site } \\
\text { management compliance checklist }\end{array}$ \\
\hline No undue delays & $\begin{array}{l}\text { Frequency of accessible buses; 'exception' gates for 'mags and } \\
\text { bags'; assistance available at train stations and at venues }\end{array}$ \\
\hline
\end{tabular}

Source: OCA, 2001

The implementation of the strategies/policies outlined in Table 3 were evaluated at various points as the Games approached via audits, walkthroughs, reviews of operational plans and questionnaires completed by people with disabilities at Olympic test events (see Figure 2) (Darcy and Woodruff 2000; Darcy 2001). The various evaluation processes identified a range of issues that needed to be addressed prior to the event. These included: the need for an Access 'Hotdesk' to aid venues in their efforts at dealing with people with disabilities; poor signage associated with toilets and other amenities; shortcomings in staff training; design problems with accessible portable toilets; and difficulties associated with some transport drop off points (OCA, 2001).

Figure 2: Summary Diagram of the Olympic Coordination Authority's Accessibility Strategy Review Process 


\section{ELEMENTS OF ACCESSIBILITY STRATEGY}

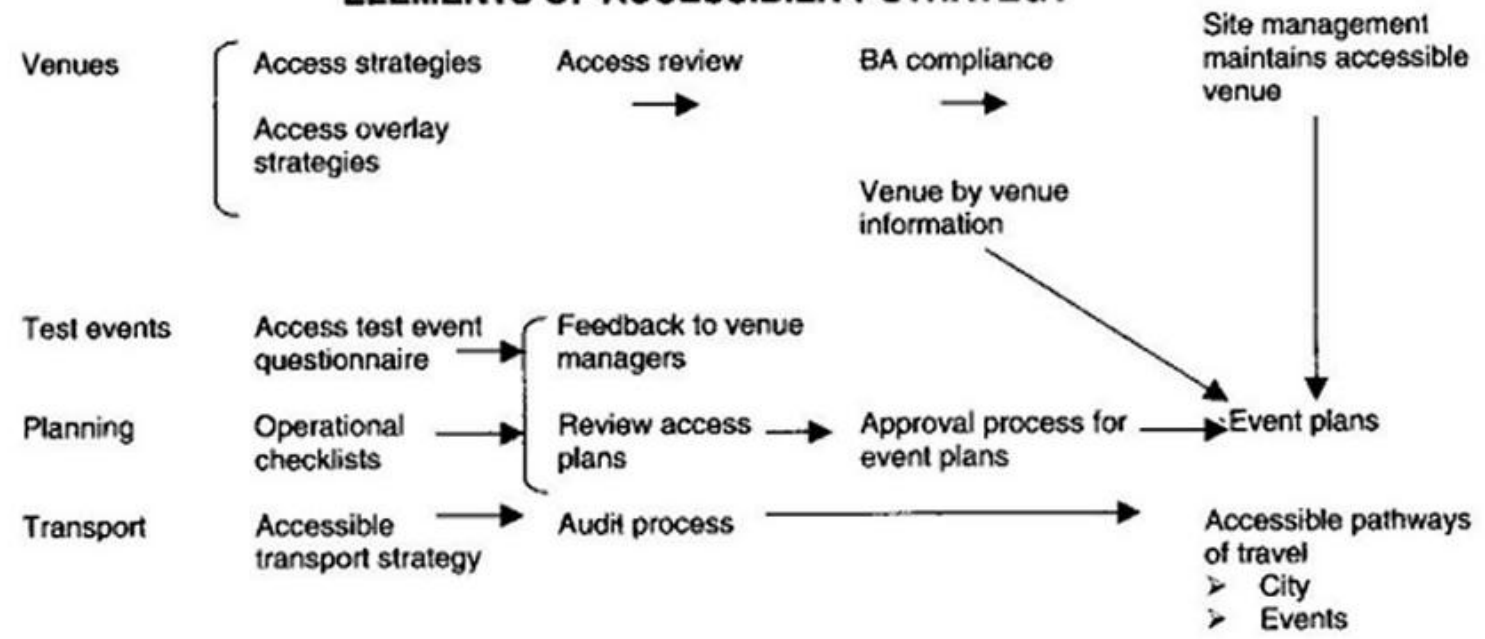

Source: OCA, 2001

While the pre-Games evaluation process was successful in identifying many potential problems, some difficulties still arose during the event itself. The major problem revolved around a significant underestimation of the number of people with disabilities attending the Games. The result of this was a range of demand related problems including a shortage of accessible buses, and of staff to provide assistance to people with disabilities. Other identified problems were associated with the ability of people to preplan their Olympic experience. This was due to the slowness of distribution of access related information and the non-contacting of ticketed spectators who had identified that they had access requirements (OCA, 2001).

The evaluation of the OCA's efforts associated with disability planning for the Games led to a range of recommendations for the ongoing development of the Disability Action Plan for events conducted at Sydney Olympic Park. These recommendations, summarised in Table 4, can also be said to provide useful insights into the general disability planning process for events.

Table 4: Recommendations for Ongoing Development of the OCA Disability Action Plan

\section{Values}

An inclusive and non-discriminatory approach to venue and event management which recognises and values diversity.

Transport

A system of accessible bus transport that is built into regular operations with set timetables etc.

Additional accessible buses.

A review of State Rail operations for people with disabilities to ensure that provisions of ramps, information and other assistance is appropriate and adequate.

A system of permanent intrasite accessible transport which can be upgraded for large events.

A parking policy which promotes accessible parking as an option to public transport use.

Ticketing 
Call centre staff and management with disability awareness training.

Maintenance of agreed percentage of accessible seating (various types).

Accurate information about seating provisions.

Carers ticketing policy.

Transparent process for managing queries and complaints.

Planning and Operations

Accessible operations fully integrated into event management.

Dedicated access team to co-ordinate access provisions, monitor outcomes and provide information as necessary.

Access provisions and improvements built into development, maintenance and refurbishment plans.

Disability awareness training and exposure to people with disabilities for all staff.

Access compliance checklists for venues and operations.

Employment and contracting of persons with disabilities with appropriate expertise.

Information

Timely and accurate information on access provisions provided to all relevant

stakeholders, eg ticketing, venues, potential patrons etc in alternate formats.

Access information included in all mainstream publicity, media etc.

Development and maintenance of technical and other material relevant to the various aspects of inclusive venue management.

Equipment

Identification, provision of necessary equipment, eg wheelchairs.

Contracting

Clear access specifications built into all contracts as essential components.

Process for assessing tenders using people with disabilities and experts in access.

Inclusion of access requirements in any transfer of responsibilities to other agencies post with the wind-up of OCA.

Consultation

Disability advisory group made up predominantly of people with disabilities.

Venue and Site Development

Access be an integral part of any proposed development

The specific issues of venue sightlines, tactile ground surface indicators, wayfinding, public art information and intrasite transport be addressed as a priority.

Seating

A capacity to decrease and/or increase the number of the number of wheelchair and companion seats to reflect the needs of particular populations, whilst at the same time ensuring that the venue is promoted as fully accessible.

Source: OCA, 2001

\section{CONCLUSION}

Disability considerations appear not to be uppermost in the minds of Australian event managers at present. This situation may well change over time as the DDA, a still relatively new piece of legislation, becomes more broadly understood by the event industry. Formal complaints concerning events and venues are being made to HREOC and identify a range of discriminatory practices. Event organisers should take the opportunity to reduce the possibility of such actions by understanding their responsibilities under the DDA and taking action to be inclusive. OCA has established a website providing access guidance for event and venue managers based on the experience of the Games (Olympic Co-ordination Authority 2002). Strategically, event managers who run events on an annual basis should develop and lodge a DAP. DAP, however, need to be well conceived if they are to be effective, and to this end a great many insights can be drawn from the Games case study. This event sought input directly from people with disabilities and peak organisations, integrated disability planning into the overall event planning process and evaluated their efforts so as to make recommendations for future events. OCA explicitly acknowledged that building access into 
events is about seeking to be inclusive of the whole community. Further, this case highlights to event organisers that inclusive planning maximises community participation, and from an instrumental perspective, it is in the interest of all event managers to do this to achieve maximum return on the resources invested. 


\section{REFERENCES}

Aslaksen, F., Bergh, S., Bringa, O. R., and Heggem, E. K. 1997, Universal Design: Planning and Design for All. The Norwegian State Council on Disability: Oslo.

Australian Building Codes Board. 1996, Building Code of Australia. CCH Australia: Canberra.

Australian Bureau of Statistics. 1996, Projections of the Populations of Australia States and Territories (Cat No. 3220.0). Australian Bureau of Statistics: Canberra.

Australian Bureau of Statistics. 1998, Disability Ageing and Carers Summary Of Findings (Cat No. 4430.0). Australian Bureau of Statistics: Canberra.

Chamie, M. 1995, What does morbidity have to do with disability? Disability and Rehabilitation, 17(7), pp. 323337.

Charlton, J. I. 1998, Nothing about us without us: disability oppression and empowerment. University of California Press: Berkeley.

Commonwealth Department of Family and Community Services. 1999, Better Physical Access. DFACS: Canberra.

Darcy, S. 2001, A Games for Everyone?: Planning for Disability and Access at the Sydney 2000 Games. Disability Studies Quarterly, 21(3), pp. 70-84.

Darcy, S., and Woodruff, J. 2000, Inclusive Sport Management Practices For Access, Disability \& Ageing Issues For The Sydney 2000 Paralympic \& Olympic Games, (Eds.), Conference proceedings of The Challenge: Sport Management Beyond 2000 - the Third International Sport Management Alliance Conference, Graduate School of Business, University of Technology, Sydney, 6-9 January 2000, pp.

Disability Council of NSW. 1994, Access Calendar. Disability Council of NSW: Sydney.

Human Rights and Equal Opportunity Commission. 2001a, Human Rights and Equal Opportunity Commission Annual Report 2000 - 2001, [Website]. Human Rights and Equal Opportunity Commission. Available: http://www.hreoc.gov.au/annrep00_01/index.html Last [2002, 1 April].

Human Rights and Equal Opportunity Commission. 2001b, Website - Disability Rights, [Website]. Human Rights and Equal Opportunity Commission. Available: http://www.hreoc.gov.au/disability_rights/ Last [2001, 23 December].

Human Rights and Equal Opportunity Commission. 2002, Register of Disability Discrimination Act Action Plans, [Website]. Human Rights and Equal Opportunity Commission. Available: http://www.hreoc.gov.au/disability_rights/action_plans/Register/register.html\#business Last [2002, 26 Dec].

Lynch, R., and Veal, A. J. 1996, Australian Leisure. Longman Cheshire: Melbourne.

New South Wales Government. 1997, NSW Government disability policy framework: a five year strategy for action: a green paper for public comment. Ageing and Disability Department NSW Health New South Wales Government: Sydney.

Olympic Co-ordination Authority. 1996, Access Guidelines (1st ed.). Olympic Co-ordination Authority: Sydney.

Olympic Co-ordination Authority. 1998, Access Guidelines (2nd ed.). Olympic Co-ordination Authority: Sydney.

Olympic Co-ordination Authority. 2001, Accessible Operations Post Game Report - Sydney 2000 Olympic and Paralympics Games. Olympic Co-ordination Authority: Sydney.

Olympic Co-ordination Authority. 2002, OCA Achieving Access Website, [Website]. Olympic Co-ordination Authority. Available: http://www.oca.nsw.gov.au/access/html/default.cfm Last [2002, 20 Decmber].

Pfieffer, D. 2002, Comparative national impairment/disability rates, DISABILITYRESEARCH@JISCMAIL.AC.UK, Sydney, pers comm. to S. Darcy, 19 April

Preiser, W. F. E., and Ostroff, E. 2001, Universal Design Handbook. McGraw-Hill: New York.

Standards Australia. 1992a, AS 1428.2 - 1992 Design for access and mobility. Enhanced and additional requirements - Buildings and facilities. ([Rev. ed.] ed.). Standards Australia: North Sydney, NSW.

Standards Australia. 1992b, AS 1428.3 - 1992 Design for access and mobility. Requirements for children and adolescents with physical disabilities. Standards Australia: North Sydney, NSW.

Standards Australia. 1992c, AS 1428.4 - 1993 Design for access and mobility. Tactile ground surface indicators for the orientation of people with vision impairment. Standards Australia: North Sydney, NSW.

Standards Australia. 1998, AS 1428.1 - 1998 Design for access and mobility. General requirements for access new buildings. (3nd ed. ed.). Standards Australia: Homebush, NSW.

Takamine, Y. 2001, The situation of disabled persons in the Asia and Pacific region. Economic and Social Commission for Asia and the Pacific (ESCAP): Japan. 
van Lin, M., Prins, R., and Zwinkels, W. 2001, The employment situation of disabled persons in the EU

(Working Paper ). Commissioned by: DG Employment and Social Affairs: ( E EIM Zoetermeer.

Wen, X., and Fortune, N. 1999, The definition and prevalence of physical disability in Australia. Australian

Institute of Health and Welfare: Canberra. 